\title{
Family Medicine Postgraduate Clinical Training in two Universities in Egypt:Physicians' Perspectives
}

\author{
Maha A.Mowafy ${ }^{1}$, Nesreen M.Kamal Elden ${ }^{2}$, Nagwa Nashat Hegazy ${ }^{3 *}$ \\ ${ }^{1}$ Family Medicine Department, ${ }^{2}$ Public Health Department, Faculty of Medicine, Cairo University, ${ }^{3}$ Family Medicine \\ Department, Faculty of Medicine, Menoufia University \\ *Corresponding Author: Nagwa Nashat Hegazy, Email: Nagwa.nashaat1@med.menofia.edu.eg
}

\begin{abstract}
Background: The Family Medicine Specialty was endorsed to fulfill the needs of qualified Primary Health Care providers. Family Medicine Postgraduate Training in Egypt had started in the universities under the umbrella of Medical Colleges in the form of postgraduate trainings and degrees.

Objectives: This paper aimed to identify the strengths and weaknesses of the different clinical rotations in Family Medicine in relation to the learning outcomes and to assess trainees' satisfaction.

Methods: A mixed research exploratory study was conducted among 48 postgraduate family physicians' candidates in their final year of training from two purposively selected universities (Cairo University and El Menoufia University) during 2019.

Results: The attitude of the physicians towards their clinical education experience differs significantly between the InternalMedicine \& Pediatrics. About $72 \%$ of participants were from Cairo University and $28 \%$ from Menoufia. Internal Medicine training was the best perceived among trained physicians. More than (71\%) of the physicians believed they understood the common clinical cases.

Conclusions: These findings can be usefulfor the policy makers to emphasize the importance of raising awareness among staff member regarding family practice and to implement the suggested recommendations and deal with obstacles to improve the Family Medicine training in order to provide effective and efficient primary care services.

Keywords: Family Medicine; Training; clinical; Satisfaction, Challenges.
\end{abstract}

\section{INTRODUCTION}

Family medicine (FM) specialty is in very high demand in Egypt for many factors. The foremost underlying cause is the high need for the services of Family Physicians (FPs) by the Egyptian community specially with the implementation of the health insurance. Other reasons include lack of qualified FPs in primary health care (PHC) facilities. National health insurance and universal health coverage rely not only on access to care, but also the quality of that care. Family physicians, with additional postgraduate training to become specialists in FM, can improve the quality of primary care, when they are part of healthcare teams. ${ }^{(1,2)}$

Family medicine specialty provides ongoing, comprehensive, and cost-effective care to the whole family within the community through the life-cycle approach and based on their needs. ${ }^{(3,4)}$. Health care services that depend on FPs are more capable to deliver such good care than specialist- based ones. This is mainly critical in developing countries where looking for lower health expenses and equitable delivery of care along with better quality health outcomes and patient satisfaction arises as a favorite policy goal ${ }^{(5)}$. Family physicians, the "gatekeepers" of PHC services ${ }^{(6)}$, are qualified to deliver first contact and continuing care to both sexes and all age groups in the societies they support. ${ }^{(3,4)}$
According to the training requirements of FM, trainees are demanded to spend a total of 18 months of training to complete the needed qualifications of the postgraduate degrees in FM. Both Master and Doctorate degrees curricula were designed to meet the trainee's practical and theoretical needs in FM in order tograduate a skilled and experienced FPs.

The training requirements include different rotations in Internal Medicine, Surgery, Pediatrics, Obstetrics and Gynecology, Orthopedics, Dermatology, ENT, Ophthalmology, Emergency Medicine, and Psychiatry ${ }^{(7,}$ 8). In comparison to other specialties, FM is an innovative field in Egypt, though in other countriessuch as the Arabian Gulf it appeals an ample number of graduated physicians than any other specialty.

The high demand on FM as a specialty due to the rapid changes in the health sector reform and needs for health insurance have extensively increased pressure on several aspects of training. This necessitates identifying difficulties or ongoing challenges in FPs' training to be properly evaluated, clarified, discussed and provide solutions. The current study was designed to show that the forms of challenges that are confronted in FM clinical rotation programs in two universities in Egypt and how it is perceived by the trained physicians $(9,10$, and 11) 


\section{METHODS}

\section{Study design:}

A mixed research method in the form of exploratory sequential design was conducted among postgraduate family physicians' candidates from two purposively selected universities (Cairo University and El Menoufia University). The exploration of the rotation nature was done with few participants followed the analysis of the results that had entailed more research in the form of the quantitative part to make sure of the obtained idea and quantify the data. The first phase, qualitative in-depth face-to-face interviews (IDI) and focus group discussions (FGDs) were used to shed the light on the rotation parts and the experience gained from it. The second phase, quantitative research inquiries had addressed the clinical examination skills required (either by observation or performance) in all the clinical rotations, intellectual skills, and the degree of satisfaction with knowledge \& skills within the rotation. (12)

\section{Settings, Sampling, and Participants:}

The estimated sample size by using Epi Info version 6 at $95 \%$ confidence interval and $8 \%$ level of precision, with $17 \%$ of physicians felt prepared in general clinical skills, ${ }^{(13)}$ design effect of 1.2 and population size of 100 candidates is 48 cases. All registered family physicians' postgraduate candidates in thetwo universities were requested to participate in the study.

For the qualitative part, a convenience sample was taken based on random purposive sampling where participants were chosen randomly from the target population family physicians finishing their training rotations. The qualitative part had included 31 participants distributed on eight in depth interviews (IDI) along with three focus group discussions (FGDs) (n1=8, $\mathrm{n} 2=7, \mathrm{n} 3=7$ ). Each session had lasted 45- $60 \mathrm{~min}$, facilitated by a moderator and a note taker. All sessions were recorded.

\section{Data collection:}

Phase one: For the qualitative part of the research an interview guided questions were used to gather data from the studied group from different rotations. It included their description for the rotation, gained experience from the rotation and the potential underprivileged part of the rotation from their point of view. Indepth face-to-face interviews (IDI) and Focus groups (FGDs) were preferred due to their ability to capture theviews on the enrolled trainees.

A cross- sectional survey was mailed, during 2019, to postgraduate residents' family physicians in their finalyear of training. The survey was mailed to all registered family physicians' postgraduate candidates from thetwo universities after the final semester. The head of the FM department from the two universities invited theresidents to complete the survey.

Questions that provide feedback on clinical training effectiveness and were appropriate to the aim of the study were carefully chosen from the Medical School Graduation Questionnaire ${ }^{(14)}$. The survey tool includes 9 items. Questions measure the attitude of the physicians towards their clinical education experience: understanding common clinical conditions, acquiring the clinical and communication skills, recommending and interpreting the diagnostic tests, observing and performing physical examination and the overall clinical education experience in each rotation. The participants rated their performance in each of the clinical rotation using a five-point Likert scale: 1(strongly agree), 2 (agree), 3 (neither agree nor disagree), 4 (disagree), 5 (strongly disagree). A section for background information was provided: sex and the rotation department.

Inclusion criteria: All registered candidates for postgraduate who completed their training rotations.

Exclusion criteria: Registered candidates who are still in the training program.

\section{Ethical consent:}

An approval of the study was obtained from Cairo University and Menoufia University Academic and Ethical Committee. An informed verbal consent of study subjects with a full right to withdraw was obtained after being briefed about the study objectives. The questionnaire was anonymous and all obtained data was kept as confidential. This work has been carried out in accordance with The Code of Ethics of the World Medical Association (Declaration of Helsinki) for studies involving humans.

\section{Statistical analysis}

Data were analyzed using IBM Statistical Package for the Social Sciences, version 24 (SPSS Inc., Chicago, IL). Numerical data were described as mean, standard deviation, while qualitative data were described as number and percentage. Then it was analyzed using a Chi-squared test (X2) to detect the relation between different qualitative variables. $P$ value of $\leq 0.05$ was considered significant.

\section{RESULTS}

For the qualitative part:

The three-category heading were namely; Strengths in the clinical rotations, challenges encountered andopportunities for a roadmap plan. The 
strength points had been categorized under the application of the proposed intended learning outcomes(ILOs) and accountability. The following are the main reported feedback from participants regarding the ILOs; participants acknowledge being able to examine and treat a wide range of acute, chronic and emergency cases and observe and train on the application of different techniques and follow up of patients till discharge. Moreover, among the strength points, participants highlighted were attendance of bed-side rounds, staff rounds and attend emergency and dealing with life threatening conditions.

Under accountability category; trained family physicians have stated being accountable and fully responsible of the inpatients in clinical rotation included inpatient care such as internal medicine. In addition to the high follow of outpatient clinics with urgent needs for decision making as more additional strength points. One of the participants said "It was a great opportunity to provide care to lots of serious and interesting cases, topractice a lot of skills, and do lots of procedures. The daily rounds and the weekly meeting were very informative and useful".

On the other hand, challenges had been categorized within infrastructural, logistics and procedural. For the infrastructural, the ration of the place per trainee and the lack of certain needed equipment's were the main specified challenges. Trainees said that they faced the following challenges related to logistical issues during their rotation in the different clinical departments: lack of responsible supervisors in the training departments, lack of orientation about the FM rotation, lack of clear job description of the trainees in the visited department and overlaps in the training schedules. One of the participants said "we weren't attached to specific doctors" indicating an important challenge.

During the implementation of the process of clinical training in rotations, participants mentioned that tight practice schedule and large numbers of trainees enrolled in the training department affected the quality of training. For example, rotations in pediatrics and internal medicine department are obligatory for all clinical specialties, accordingly the number of trainees are large.

From the discussion and interviews with participants it was noticed that the strong support from faculty management in adopting the FM concept and the implementation of Health Insurance System at the national level, in addition to MOHP in primary health care reform and the cooperative attitude from the colleagues working in different departments are the main opportunities that should be considered for improvement.

A road maps toward improving the FM training are to unify the training in the terms of department and duration and standardization of required skills among different universities in each clinical rotation.

\section{For the quantitative part:}

The survey response rate was about $88 \%$. About $72 \%$ were from Cairo University and 28\% from Menoufia University. Figure (1) showed that about $83 \%$ of the family physicians in the two universities were female.

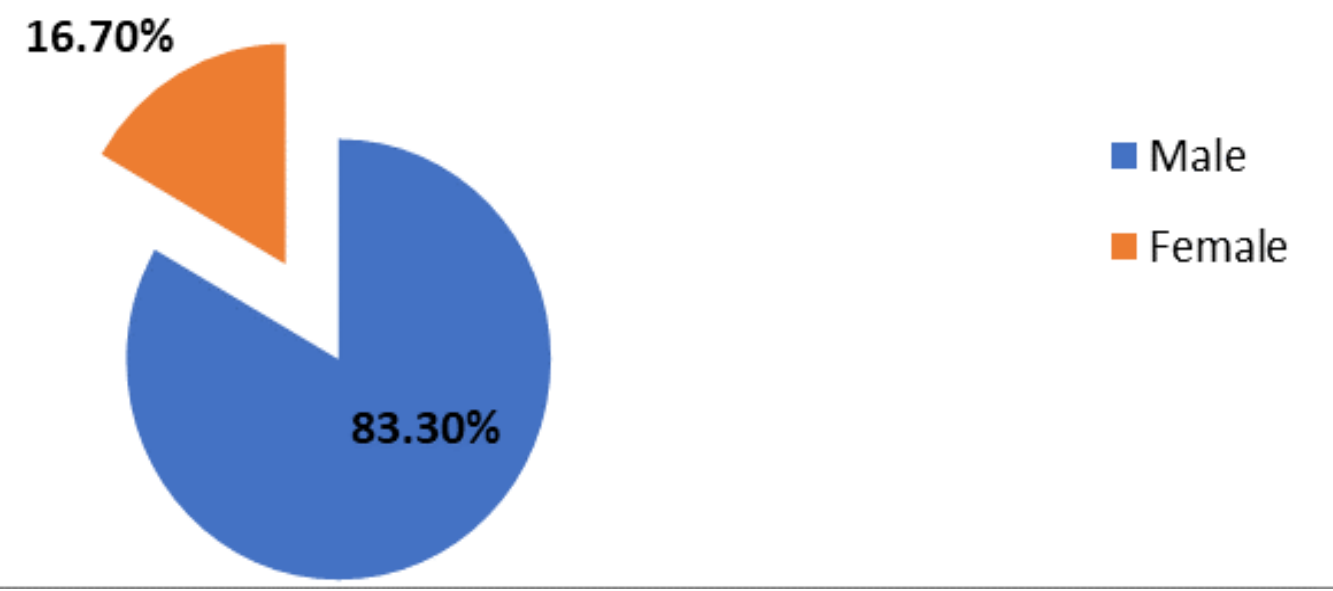

Figure 1: Sex distribution of the study participants 
Table (1) showed that although more than $71 \%$ of the physicians believed they understood the common clinicalcases with their management during the Internal Medicine rotations, only $12 \%$ were confident of their ability to perform the patients' physical examination. Half of the FM physicians agreed that they acquired the clinical skills of the Internal Medicine. On the other hand, less than $12 \%$ of the physicians believed they acquired the required clinical skills of the Pediatric Medicine and this difference is statisticallysignificant ( $\mathrm{p}$ $\mathrm{P} \leq 0.001$ ). $64.3 \%$ and $59.5 \%$ of the physicians believed they have acquired the necessary communication skills during the Internal Medicine and Pediatric Medicine rotations, respectively with no statistical significance difference $(\mathrm{P}=0.4)$. The attitude of the physicians towards their clinical education experience differed significantly between the Internal Medicine and the Pediatric rotation in the following: understanding common clinical conditions $(\mathrm{P} \leq 0.001)$, recommending and interpreting the diagnostic tests $(\mathrm{P}=0.04)$, observing and performing physical examination $(\mathrm{P}=0.002)$ and the overall clinical education experience in each rotation $(\mathrm{P}=0.006)$.

Table (1): Percent of physicians' positive attitude towards clinical education experience in internalMedicine and Pediatrics departments

\begin{tabular}{|c|c|c|c|c|c|}
\hline & \multicolumn{2}{|c|}{ Internal Medicine } & \multicolumn{2}{|c|}{ Pediatrics } & \multirow[b]{2}{*}{ P value } \\
\hline & $\begin{array}{c}\text { Positive } \\
\text { responses } \\
(\mathrm{n}=42)\end{array}$ & $\%$ & $\begin{array}{l}\text { Positive } \\
\text { responses } \\
(\mathrm{n}=42)\end{array}$ & $\%$ & \\
\hline $\begin{array}{l}\text { I am confident that I have acquired the } \\
\text { required clinical skills }\end{array}$ & 21 & $50.0 \%$ & 5 & $11.9 \%$ & $\leq 0.001$ \\
\hline $\begin{array}{l}\text { I have the fundamental understanding } \\
\text { of common conditions and their } \\
\text { management }\end{array}$ & 30 & $71.4 \%$ & 8 & $19.1 \%$ & $\leq 0.001$ \\
\hline $\begin{array}{l}\text { I have the communication skills } \\
\text { necessary to interact with patients and } \\
\text { health professionals }\end{array}$ & 25 & $59.5 \%$ & 27 & $64.3 \%$ & 0.41 \\
\hline $\begin{array}{l}\text { I am confident that I can perform a } \\
\text { physical examination }\end{array}$ & 5 & $11.9 \%$ & 16 & $38.1 \%$ & 0.006 \\
\hline $\begin{array}{l}\text { Prioritize a differential diagnosis } \\
\text { following a clinical examination }\end{array}$ & 25 & $59.5 \%$ & 25 & $59.5 \%$ & 0.9 \\
\hline $\begin{array}{l}\text { Recommend and interpret common } \\
\text { diagnostic and screening tests }\end{array}$ & 24 & $57.1 \%$ & 14 & $33.3 \%$ & 0.04 \\
\hline $\begin{array}{l}\text { I believe I am adequately prepared to } \\
\text { care for patients from different } \\
\text { backgrounds }\end{array}$ & 25 & $59.5 \%$ & 11 & $26.2 \%$ & 0.004 \\
\hline $\begin{array}{l}\text { You were observed performing the } \\
\text { relevant portions of physical } \\
\text { examination }\end{array}$ & 6 & $14.3 \%$ & 20 & $47.6 \%$ & 0.002 \\
\hline $\begin{array}{l}\text { I am confident that my educational } \\
\text { experience is of good quality }\end{array}$ & 22 & $52.4 \%$ & 10 & $23.8 \%$ & 0.006 \\
\hline
\end{tabular}

More than $64 \%$ and $57.1 \%$ of the physicians understood the management of common clinical conditions inSurgery and Gynecology and Obstetrics, respectively with no statistical significance difference $(\mathrm{P}=0.7)$. Although training on clinical skills is important for Gynecology and Obstetrics and Surgery, only one third of the physicians and $28.6 \%$ of the physicians acquired the required clinical skills, respectively with no statistical significance difference $(\mathrm{P}=0.8)$. About $70 \%$ of the physicians believed they are prepared to adequately care for patients after the Surgery rotation versus $26.2 \%$ of them after the Gynecology and Obstetrics and this difference was statistically significant difference $(\mathrm{P} \leq 0.001)$ as shown in table (2). 
Table 2 Percent of physicians' positive attitude towards clinical education Experience in Surgery andGynecology and obstetrics departments

\begin{tabular}{|c|c|c|c|c|c|}
\hline & \multicolumn{2}{|c|}{ Surgery } & \multicolumn{2}{|c|}{ Gynecology/obstetrics } & \multirow[t]{2}{*}{ P value } \\
\hline & $\begin{array}{l}\text { Positive } \\
\text { response } \\
\mathrm{S} \\
(\mathrm{n}=42)\end{array}$ & $\%$ & $\begin{array}{l}\text { Positive } \\
\text { response } \\
\mathrm{S} \\
(\mathrm{n}=42)\end{array}$ & $\%$ & \\
\hline $\begin{array}{l}\text { I am confident that I have } \\
\text { acquired the required clinical } \\
\text { skills }\end{array}$ & 12 & $\begin{array}{c}28.6 \\
\%\end{array}$ & 14 & $33.3 \%$ & 0.8 \\
\hline $\begin{array}{l}\text { I have the } \\
\text { fundamental } \\
\text { understanding of } \\
\text { common } \\
\text { conditions and their } \\
\text { management }\end{array}$ & 27 & $\begin{array}{c}64.3 \\
\%\end{array}$ & 24 & $57.1 \%$ & 0.7 \\
\hline $\begin{array}{l}\text { I have the communication } \\
\text { skillsnecessary to } \\
\text { interact } \\
\text { with } \\
\text { patients and health } \\
\text { professionals }\end{array}$ & 31 & $\begin{array}{c}73.8 \\
\%\end{array}$ & 23 & $54.8 \%$ & 0.06 \\
\hline $\begin{array}{l}\text { I am confident that I can } \\
\text { perform } \\
\text { a physical examination }\end{array}$ & 13 & $\begin{array}{c}31.0 \\
\%\end{array}$ & 11 & $26.2 \%$ & 0.4 \\
\hline $\begin{array}{l}\text { Prioritize a differential } \\
\text { diagnosis } \\
\text { following a clinical } \\
\text { examination }\end{array}$ & 15 & $\begin{array}{c}35.7 \\
\%\end{array}$ & 9 & $21.4 \%$ & 0.1 \\
\hline $\begin{array}{l}\text { Recommend and interpret } \\
\text { common diagnostic } \\
\text { and screening tests }\end{array}$ & 24 & $\begin{array}{c}57.1 \\
\%\end{array}$ & 21 & $50.0 \%$ & 0.4 \\
\hline $\begin{array}{l}\text { I believe I am } \\
\text { adequatelyprepared to care } \\
\text { for patients from } \\
\text { different backgrounds }\end{array}$ & 29 & $\begin{array}{c}69.0 \\
\%\end{array}$ & 11 & $26.2 \%$ & $\leq 0.001$ \\
\hline $\begin{array}{l}\text { You were observed } \\
\text { performing } \\
\text { the relevant portions of } \\
\text { physicalexamination }\end{array}$ & 27 & $\begin{array}{c}64.3 \\
\%\end{array}$ & 19 & $(45.2 \%)$ & 0.06 \\
\hline $\begin{array}{l}\text { I am confident that my } \\
\text { educational experience is of } \\
\text { goodquality }\end{array}$ & 20 & $\begin{array}{c}47.0 \\
\%\end{array}$ & 21 & $50 \%$ & 0.5 \\
\hline
\end{tabular}

Table (3) showed that more than $47 \%$ of the family physicians acquired the required clinical skills in ENT and Psychiatrics. On the other hand, $38.1 \%$ and $26.2 \%$ gained the required clinical skills in Dermatology and Ophthalmology, respectively with no statistical significance difference $(\mathrm{P}=0.14)$. Themajority of the physicians understood the management of the fundamental clinical cases of Psychiatrics, Dermatology, Ophthalmology and ENT with no statistical significance difference $(\mathrm{P}=0.195)$. The attitude of the physicians towards their clinical education experience differed significantly between the ENT, Ophthalmology, Dermatology and Psychiatrics in the following: acquiring the communication skills $(\mathrm{P}=0.007)$, recommending and interpreting the diagnostic tests $(\mathrm{P} \leq 0.001)$, observing and performing physical examination $(\mathrm{P}=0.006)$ and being prepared to care for patients $(\mathrm{P}=0.006)$. 
Table 3 Physicians' Perspectives towards clinical education Experience in ENT, Ophthalmology, Psychiatrics and Dermatology departments

\begin{tabular}{|c|c|c|c|c|}
\hline & ENT & $\begin{array}{l}\text { Ophthalmolog } \\
y\end{array}$ & $\begin{array}{c}\text { Dermatolog } \\
\mathbf{y}\end{array}$ & Psychiatry \\
\hline & $\begin{array}{c}\text { Positive } \\
\text { response } \\
\mathrm{s} \\
(\mathrm{n}=42) \\
(\%)\end{array}$ & $\begin{array}{l}\text { Positive } \\
\text { responses }(n=42) \\
(\%)\end{array}$ & $\begin{array}{l}\text { Positive } \\
\text { response } \\
\mathrm{s} \\
(\mathrm{n}=42)(\%)\end{array}$ & $\begin{array}{l}\text { Positive } \\
\text { response } \\
\text { s } \\
(n=42)(\%)\end{array}$ \\
\hline $\begin{array}{l}\text { I am confident that I have acquired } \\
\text { the } \\
\text { required clinical skills }\end{array}$ & $20(47.6 \%)$ & $11(26.2 \%)$ & $16(38.1 \%)$ & $20(47.6 \%)$ \\
\hline $\mathrm{P}$ value & \multicolumn{4}{|c|}{0.14} \\
\hline $\begin{array}{l}\text { I have the fundamental understanding } \\
\text { of } \\
\text { common conditions and their } \\
\text { management }\end{array}$ & $30(71.4 \%)$ & $28(66.7 \%)$ & $29(69.0 \%)$ & $36(85.7 \%)$ \\
\hline $\mathrm{P}$ value & \multicolumn{4}{|c|}{0.195} \\
\hline $\begin{array}{l}\text { I have the communication skills } \\
\text { necessary to interact with patients } \\
\text { andhealth professionals }\end{array}$ & $24(57.1 \%)$ & $9(21.4 \%)$ & $28(66.7 \%)$ & $17(40.5 \%)$ \\
\hline $\mathrm{P}$ value & \multicolumn{4}{|c|}{0.007} \\
\hline $\begin{array}{l}\text { I am confident that I can perform } \\
\text { a } \\
\text { physical examination }\end{array}$ & $14(33.3 \%)$ & $21(50.0 \%)$ & $28(66.7 \%)$ & $15(35.7 \%)$ \\
\hline P value & \multicolumn{4}{|c|}{0.23} \\
\hline $\begin{array}{l}\text { Prioritize a differential diagnosis } \\
\text { following a clinical examination }\end{array}$ & $14(33.3 \%)$ & $16(38.0 \%)$ & $22(52.3 \%)$ & $11(26.2 \%)$ \\
\hline $\mathrm{P}$ value & \multicolumn{4}{|c|}{0.008} \\
\hline $\begin{array}{l}\text { Recommend and interpret } \\
\text { common } \\
\text { diagnostic and screening tests }\end{array}$ & $24(57.1 \%)$ & $21(50.0 \%)$ & $30(71.4 \%)$ & $9(21.4 \%)$ \\
\hline $\mathrm{P}$ value & \multicolumn{4}{|c|}{$\leq 0.001$} \\
\hline $\begin{array}{l}\text { I believe I am adequately prepared } \\
\text { to } \\
\text { care for patients from different } \\
\text { backgrounds }\end{array}$ & $4(9.5 \%)$ & $22(52.4 \%)$ & $22(52.4 \%)$ & $15(35.7 \%)$ \\
\hline $\mathrm{P}$ value & \multicolumn{4}{|c|}{0.006} \\
\hline $\begin{array}{l}\text { You were observed performing } \\
\text { the } \\
\text { relevant portions of physical } \\
\text { examination }\end{array}$ & $12(28.6 \%)$ & $19(45.2 \%)$ & $28(66.7 \%)$ & $21(50.0 \%)$ \\
\hline $\mathrm{P}$ value & \multicolumn{4}{|c|}{0.006} \\
\hline $\begin{array}{l}\text { I am confident that my } \\
\text { educational } \\
\text { experience is of good quality }\end{array}$ & $26(61.9 \%)$ & $20(47.6 \%)$ & $21(50 \%)$ & $20(47.6 \%)$ \\
\hline $\mathrm{P}$ value & \multicolumn{4}{|c|}{0.5} \\
\hline
\end{tabular}




\section{DISCUSSION}

This study focused on highlighting the most significant strengths, weakness and challenges faced in FM training from the registered physicians for postgraduate degrees perspective. Strength points had been categorized under the application of the proposed intended learning outcomes and accountability. This study revealed many challenges related to infrastructural, logistic and procedural areas. These include insufficient space for training such as small examination and education rooms, lack of portable medical equipment's, and absence of standard clinical guidelines. Comparable results and observations were stated earlier by Al-Khaldi et al. ${ }^{(15)}$ in 2014 in Saudi Arabia and another one by Bin Abdulrahman and Al-Dakheel (16). It is similarly noticed, in additional study implemented by AlKhathami ${ }^{(17)}$ that training facilities were among the most reported challenges confronted by trainees during FM rotations inSaudi Arabia.

In the current study, it was observed that the number of trainers was insufficient for the majority of the training rotations, most of them has other clinical loads. The present study showed that staff in clinical departments responsible for FM training have clinical experience, but inadequate in number and lack enough information about the FM training needs. Also, the combination of senior and junior trainers is a great environment in FM. Training even with the fact of the "generations' gaps"(18). Both can be encouraged to work collaboratively with well-designed and clear job descriptions in view of the experiences and diverse roles of trained family physicians in different clinical rotations. To overcome these challenges a well-designed orientation course for all trainers emphasizing on the FM training main objectives, actual need and intended learning outcomes is a necessity.

This study provided indication at university level in Egypt that a FM rotation can produce tangibly measured improvement in knowledge and attitude that are greater to those from a just didactic course as perceived by the trainees. This echo the results of Bahn et al. (19) comparing FM and internal medicine rotations' knowledge, whereknowledge in several rotations of FM was extensively enhanced among the trained physicians, except for basic concepts in FM, that was not clearly communicated by other departments. Internal Medicine and Pediatric were the best stated rotation for gained knowledge. This presented the importance of clinical rotations in implementing continuous, complete and preventive health service to patients.

Although knowledge changes could be contributed to what trainees previously exposed to from the theoretical sessions, attitude variation reflects a more evocative improvement as reported by trainees after the training rotation. The study findings are consistent with other studies that demonstrated a positive impact on trainee's attitude after FM rotations ${ }^{(20,21)}$.

The study showed that knowledge upgrading observed in all rotations of FM, in comparison with communication skills this was controversial to Tandetert et al. ${ }^{(22)}$ study where communication skill changes among participants in FM could be seen in the area of provision of mental health care and regular check-ups. This could be linked to various factors. First, trainees exposed to mental health cases that were infrequently encountered. Second, communication skills for other conditions as chronic disease diagnosis could be face in different clinical trainings prior to FM rotations. The small sample size of both studies (30 students) for Tandetert et al. (22) and 42 trainees for this study, could clarify the absence of notable change in skills. Numerous students in Bahn $\boldsymbol{e t}$ al. ${ }^{(19)}$, Duncan et al. ${ }^{(24)}$ and Bosner et al. ${ }^{(25)}$ studies recommended training via case studies to be extended, also more practice settings to be conducted, to guarantee satisfactory time for practice and to permit for more clinical experience. This goes hand in hand with the results of this study, which sets more emphasis on clinical skills as reported by FPs in all rotations throughout their postgraduate training.

The shortage of satisfaction with performing clinical skill stated by trainees could be related to the fact that FM rotations took place in different departments and with variable duration of training ranging from one month for ophthalmology to six months for Internal Medicine. Though, this partiality could be explained bythe minimum input of training modules such as ophthalmology, earnose-throat to the FM rotation. Further studies should be carried out for different rotation over time with more focus on the clinical skills and to identify formats and content of these rotations and their effects. Moreover, the law reported rate of acquired clinical skills during different rotations could be explained by theobserved fact that a lot of the trainees started the postgraduate training program after either completing their internship immediately or after shifting their carrier after being enrolled in other program without any experience in FM. Accordingly, it would be preferable that registered trainees spend at least few months at FM department before joining the clinical rotations, which will give them a better chance to understand the concepts and needs of FM practice. One more significant suggestion is to give registered postgraduate trainees appropriate orientation session, which explains the core elements of training program (objectives, contents, methods of assessment, few relevant references, different bylaws, regulation, policies and procedures) with a clear job description.

For challenges linked to low competency of trainees, some important actions related to formative assessment and improvement might be applied. Such as, 
improving supervisions, particularly during the performance of clinical examination, ongoing \& continuous assessment, such as case-based discussion, mini-clinical examination, and direct observation feedbacks. The above mentioned will encourage active contribution of trainees, recognition of weakness areas and instant feedback to trainees by the supervisor or mentor. Moreover, this method will guarantee patient safety and improved quality of services as well as documentation and reporting. Finally, application of portfolio to attain the aims of the clinical training with frequent mentoring by the supervisors must be established $(26,27)$

In what way to organize a FM rotation has been stated in numerous studies. This could be supported by the feedback from trainees to provide significant guide for faculty and university leaders to continually boost training and education activities, organization and details of this rotation. A general study of mandatory skillsin clinical rotations in a number of universities in the United States showed that clinical rotations should be done using a combination of FM centers and community facilities. This differs from training rotation in the studied universities where clinical rotations based on coordination and collaboration with different clinical departments ${ }^{(28)}$.

\section{Study Limitation:}

There were some limitations in this study, that should be addressed in future research. First, the time constrains between the end of the training rotations and requesting the candidates to fill the online survey, especially that trainees were preparing themselves for the exams. Second, the survey was shared with the participants after completing their rotations and not an ongoing with the training rotations, this limited thechance of immediate improvement of the weakness during the training process. In addition, the clinical rotations had different duration, which made the comparison more difficult.

\section{CONCLUSION}

The study showed that FM training in the two universities is facing numerous challenges. Internal Medicine and Pediatric rotations were the best perceived by physicians. Other rotations were less satisfactory, this could raise a flag on whether satisfaction and positive attitude is linked to the duration of therotation or other factors. Further studies are needed to focus more on each specialty training rotation to find out common success and satisfaction factors. These findings could support the policy makers to emphasize the importance of raising awareness among staff member regarding family practice and to apply the recommended actions and manage obstacles to upgrade the FM training in order to deliver effective and competent health care services. Moreover, it is recommended to support the availability and use of national guidelines for common health problems, such as obesity, hypertension, asthma, dyslipidemia and acute respiratory and gastrointestinal tract diseases to have a standardized training among FM departments in all universities, this approach could result in high-quality training and improving the level of performance of trainees registered at different training of FM.

\section{Financial support and sponsorship: Nil. Conflict of interest: Nil.}

\section{ACKNOWLEDGMENT}

The authors express their thanks to trainees in both FM Department for activeparticipation and collaboration during the process of data collection.

\section{REFERENCES}

1. Von Pressentin K, Mash R, Baldwin-Ragaven $L$ et al. (2018): The bird's-eye perspective: how do district health managers experience the impact of family physicians within the South African district health system? A qualitative study. South African Fam Pract., 60: 13-20.

2. Von Pressentin K, Mash R, Baldwin-Ragaven $L$ et al. (2018): The perceived impact of family physicians on the district health system in South Africa: a cross-sectional survey. BMC Fam Pract., 19: 24.

3. Haq C, Ventres W, Hunt V et al. (1995): Where there is no family doctor: The development of family practice around the world. Academic Medicine, 70: 370-80.

4. Gay B (2013): What's New in the Updated European Definition of General Practice/Family Medicine?J Gen Pract., 1(2):111.

5. WHO (2004). What are the advantages and disadvantages of restructuring a health care system to be more focused on primary care services? Copenhagen, Denmark: WHO Regional Office for https://www.euro.who.int/_data/assets/pdf_file/0004/747 04/E82997.pdf

6. Watt W (1987): The family physician: Gatekeeper to the health-care system. Canadian Family Physician, 33: 11014.

7. Saudi commission for health specialties (2011): Saudi board of family medicine. Training Manual, 2 nd ed., Pp: 15.

8. Saudi commission for health specialties (2011): Saudi diploma of family medicine. Training Manual. 2nd ed., Pp: 10.

9. Bin Abdulrahman K, Al-Dakheel A (2006), Family medicine residency program in Kingdom of Saudi Arabia: Residents opinion. Pak J Med Sci., 22: 250-7

10. Al-Shehri A (2004) Family and community medicine in Saudi Arabia. Development and future. Saudi Med J., 25: 1328-30.

11. Osman H, Romani M, Hlais $S$ (2011). Family medicine in Arab countries. Fam Med., 43: 37-42.

12. Creswell J W, Plano C V L, Gutmann M L et al. (2017): Advanced mixed methods research designs. In A. Tashakori 
\& C. Teddlie (Eds.), Handbook of mixed methods in social and behavioral research Thousand Oaks, CA: SAGE Publications, Pp: 209-240.

13. Tokuda Y, Goto E, Otaki J et al. (2010): Undergraduate educational environment, perceived preparedness for postgraduate clinical training, and pass rate on the National Medical Licensure Examination in Japan. BMC medical education, 10 (1): 35.

14. The Association of American Medical College (AAMC) Medical School (2020): The Association of American Medical College (AAMC) Medical School Graduation Questionnaire. Available from https://www.aamc.org/ Accessed on

15. Al-Khaldi Y, AlDawood K, Al-Shmmari S, Al-Yahya $O$ (2014): Challenges facing postgraduate training in family medicine in Saudi Arabia: Patterns and solutions. Journal of Health Specialties, 2 (2): 61-67.

16. Bin Abdulrahman K, Al-Dakheel A (2006): Family medicine residency program in Kingdom of Saudi Arabia: Resident's opinion. Pak J Med Sci., 22: 250-7.

17. AL-Khathami A (2012): Evaluation of Saudi family medicine training program: The application of CIPP evaluation form. Med Teach., 34: S81-9.

18. Lim A, Epperly T (2013): Generation gaps: Effectively leading physicians of all ages. Fam Pract Manag., 20: 29-34.

19. Bahn T, Cronau H, Way D (2003): A comparison of family medicine and internal medicine experiences in a combined clerkship. Fam Med., 35 (7): 499- 503

20. Turkeshi E, Michels N, Hendrickx K, Remmen $R$ (2015): Impact of family medicine clerkships in undergraduate medical education: a systematic review. BMJ Open, 5 (8): e008265.
21. Thistlethwaite J, Kidd M, Hudson J (2007): General practice: a leading provider of medical student education in the 21st century? Med J Aust., 187 (2): 124-8.

22. Tandeter H, Carelli F, Timonen M et al. (2011): A 'minimal core curriculum' for family medicine in undergraduate medical education: a European Delphi survey among EURACT representatives. Eur J Gen Pract., 17 (4): 217-20.

23. Irby D (1995): Teaching and learning in ambulatory care settings: a thematic review of the literature. Acad Med., 70 (10): 898-931.

24. Duncan G, Roth L, Donner-Banzhoff N et al. (2016): Teaching points-do they occur and what do they contain? An observation study concerning the general practice rotation. BMC Med Educ., 16: 113.

25. Bosner S, Roth L, Duncan G et al. (2017): Verification and feedback for medical students: an observational study during general practice rotations. Postgrad Med J., 93 (1095): 3-7.

26. Norcini J (2010): Workplace assessment. Understanding medical education evidence, theory and practice. Swanwick T, editor. London: Blackwell Publisher, Pp: 233-45.

27. Ross S, Poth C, Donoff M et al. (2011): Competencybased achievement system using formative feedback to teach and assess family medicine residents' skills.Can Fam Physician, 57: e323-30.

28. Tandeter H, Carelli F, Timonen M et al. (2011): A 'minimal core curriculum' for family medicine in undergraduate medical education: a European Delphi survey among EURACT representatives. Eur J Gen Pract., 17 (4): 217-20. 